\title{
Synthesis and Structure of Methoxo-Terminated
}

\section{Molybdenum and Tungsten $\mathrm{M}_{3} \mathrm{~S}_{4}$ Clusters Containing}

\section{Aminophosphine Ligands}

Tomás F. Beltrán ${ }^{a}$ and Rosa Llusara,*

a Departament de Química Física i Analítica, Universitat Jaume I, Av. Sos Baynat s/n, 12071 Castelló, Spain

AUTHOR EMAIL ADDRESS: * author for correspondence: rosa.llusar@uji.es

TITLE RUNNING HEAD:

CORRESPONDING AUTHOR FOOTNOTE

a Dept. de Química Física i Analítica, Universitat Jaume I, Av. Sos Baynat s/n, 12071 Castelló, Spain: E-mail: rosa.llusar@uji.es; Tel: +34 964728086; Fax: +34 964728066; Homepage: http://www.gruporllusar.uji.es

This work is dedicated to Professor Miguel Julve on the occasion of his $65^{\text {th }}$ birthday 


\section{Table of contents}

New methoxo-terminated $\mathrm{M}_{3} \mathrm{~S}_{4}(\mathrm{M}=\mathrm{Mo}, \mathrm{W})$ clusters bearing aminophosphine ligands have been isolated in high yields by reaction of their halide precursors with methanol in the presence of triethylamine $\left(\mathrm{Et}_{3} \mathrm{~N}\right)$. Both tungsten and molybdenum derivatives have been fully characterized by spectroscopic, mass spectrometric and X-ray techniques. The crystal structures of $\left.\left[\mathrm{Mo}_{3} \mathrm{~S}_{4}\left(\mathrm{OCH}_{3}\right)_{3}\right](\mathrm{edpp})_{3}\right] \mathrm{BPh}_{4}\left(\mathbf{1}\left(\mathrm{BPh}_{4}\right)\right)$ and $\left.\left[\mathrm{W}_{3} \mathrm{~S}_{4}\left(\mathrm{OCH}_{3}\right)_{3}\right](\mathrm{edpp})_{3}\right] \mathrm{BPh}_{4}\left(2\left(\mathrm{BPh}_{4}\right)\right)$ with edpp = 2-aminoethyl)diphenylphosphine confirm that one methoxo group coordinates each metal centre. Gas-phase dissociation of the novel methoxo cluster cations using ESI tandem mass spectrometry is also presented. 


\begin{abstract}
Trinuclear $\left.\left[\mathrm{M}_{3} \mathrm{~S}_{4}\left(\mathrm{OCH}_{3}\right)_{3}\right](\mathrm{edpp})_{3}\right]^{+}$complexes, $\quad \mathbf{1}^{+} \quad(\mathrm{M}=\mathrm{Mo})$ and $\mathbf{2}^{+} \quad(\mathrm{M}=\mathrm{W})$ bearing (2aminoethyl)diphenylphosphine (edpp), have been isolated and fully characterized. Molybdenum and tungsten halide precursors react with methanol in the presence of $\mathrm{Et}_{3} \mathrm{~N}$, to yield the respective methoxoterminated clusters. The crystal structures of complexes $\mathbf{1}^{+}$and $\mathbf{2}^{+}$confirm that methoxo ligands are coordinated to the metal centres. Gas-phase dissociation of the novel methoxo cluster cations using ESI tandem mass spectrometry reveals the sequential elimination of three neutral methanol molecules under Collision Induced Dissociation (CID) conditions to form metal/imino M=NH cluster species.
\end{abstract}

\title{
Introduction
}

Transition metal alkoxo complexes are attractive targets in catalysis due to the mechanistic possibilities that emerge from the high polarity of the metal-oxygen bonds and the presence of lone pairs in the oxygen atom. Insertion of unsaturated molecules into the metal-oxygen lies in the principles of $\mathrm{CO}_{2}$ activation.[1, 2] However, the high reactivity of transition metal alkoxides and their tendency to decompose makes difficult the design of rational approaches towards the synthesis of this kind of complexes.[3] Substitution of halide ligands by strongly donating alkoxo groups has been successfully applied for the preparation of mononuclear molybdenum and tungsten methoxo complexes. [4]

In the last years, our group has prepared a series of molybdenum and tungsten $\mathrm{M}_{3} \mathrm{Q}_{4}(\mathrm{Q}=\mathrm{S}$ or Se) clusters containing outer halide and diphosphine, aminophopshine, diamine or diimine ligands. [517] In the course of our work, difficulties arise when attempting to replace the terminal halide groups by hydroxo or alkoxo ligands due to cluster decomposition and/or oligomerization. In the case of the dmpe (1,2-bis(dimethylphosphino)ethane) derivatives, we have been able to isolate hydroxo-terminated $\left[\mathrm{M}_{3} \mathrm{~S}_{4}(\mathrm{OH})_{3}(\mathrm{dmpe})_{3}\right]^{+}(\mathrm{M}=\mathrm{Mo}, \mathrm{W})$ clusters by taking advantage of the bulky characteristics of the diphosphane ligands which prevent them from decomposition.[18, 19] In contrast, alkoxo terminated 
diphosphane $\left[\mathrm{M}_{3} \mathrm{~S}_{4}(\mathrm{dmpe})_{2}(\mathrm{O})(\mathrm{OR})\right]^{+}$clusters have only been identified in gas-phase using mass spectrometric techniques. [19-21] As a result, there is a lack of structural information concerning $\mathrm{M}_{3} \mathrm{~S}_{4}$ alkoxo clusters both in the solid state and in solution. Recently, we have reported the synthesis and structure of a series of molybdenum and tungsten aminophosphine $\mathrm{M}_{3} \mathrm{~S}_{4}$ clusters containing the edpp (2aminoethyl)diphenylphosphine)) ligand, represented in Figure 1. [14, 17, 22] Remarkably, only the isomer with the three phosphorous atoms lying trans to the capping sulfur has been observed and its structure is preserved in solution without any signs of hemilability of the bidentate ligand. Reactivity studies show that substitution of the bromide ligands in $\left[\mathrm{W}_{3} \mathrm{~S}_{4} \mathrm{Br}_{3}(\mathrm{edpp})_{3}\right]^{+}$by chloride or thiocyanate easily occurs at room temperature while no reaction is observed for its diphosphino analog. [14] Further investigation of the reactivity of the $\left[\mathrm{W}_{3} \mathrm{~S}_{4} \mathrm{Br}_{3}(\mathrm{edpp})_{3}\right]^{+}$cluster cation toward bases allowed us to fully characterized the hydroxo-terminated $\left[\mathrm{W}_{3} \mathrm{~S}_{4}(\mathrm{OH})_{3}(\mathrm{edpp})_{3}\right]^{+}$complex which exhibits an stability similar to that of its dmpe analog probably due to the bulkiness of the outer ligands, which would hinder oligomerization.[22]

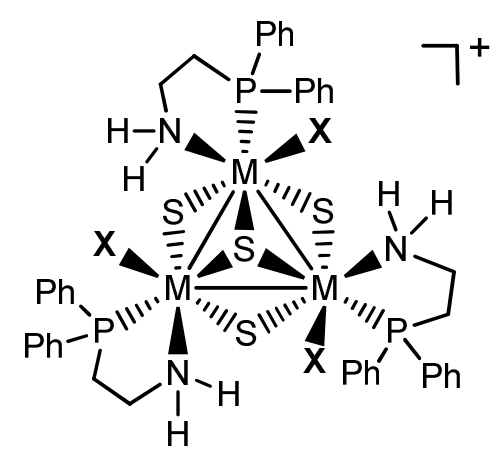

Figure 1. Structure of $\left[\mathrm{M}_{3} \mathrm{~S}_{4} \mathrm{X}_{3}(\mathrm{edpp})_{3}\right]^{+}$cations $(\mathrm{M}=\mathrm{Mo}, \mathrm{W} ; \mathrm{X}=$ halide, pseudohalide, $\mathrm{OH})$.

Motivated by the importance of alkoxo complexes in catalysis, we decided to design a synthetic procedure aimed to functionalize the aminophosphine $\mathrm{M}_{3} \mathrm{~S}_{4}$ cluster core with methoxo terminal ligands. Herein, we present the synthesis and crystal structure of two alkoxo complexes $\left[\mathrm{Mo}_{3} \mathrm{~S}_{4}\left(\mathrm{OCH}_{3}\right)_{3}(\mathrm{edpp})_{3}\right]^{+}\left(\mathbf{1}^{+}\right)$and $\left[\mathrm{W}_{3} \mathrm{~S}_{4}\left(\mathrm{OCH}_{3}\right)_{3}(\mathrm{edpp})_{3}\right]^{+}\left(\mathbf{2}^{+}\right)$. Results on the gas phase dissociation of the new complexes are also presented. 


\section{Results and Discussion}

\section{Synthesis and molecular structure}

The design of efficient synthetic protocols is essential for the development of transition metal cluster chemistry. We have recently reported that the aminophosphine (2-aminoethyl)diphenylphosphine (edpp) can be readily coordinated to the trimetallic $\mathrm{M}_{3} \mathrm{~S}_{4}$ unit through excision of one-dimensional $\left\{\mathrm{M}_{3} \mathrm{~S}_{7} \mathrm{X}_{4 / 2} \mathrm{X}_{2}\right\}_{\mathrm{n}}(\mathrm{M}=\mathrm{Mo}, \mathrm{W} ; \mathrm{X}=\mathrm{Cl}, \mathrm{Br})$ polymeric phases or by reacting molecular $\left[\mathrm{Mo}_{3} \mathrm{~S}_{7} \mathrm{X}_{6}\right]^{2-}(\mathrm{X}=\mathrm{Cl}$, Br) cluster species with the aminophosphine ligand. These two approaches have allowed us to isolate a family of molybdenum and tungsten trinuclear cations of general formula $\left[\mathrm{M}_{3} \mathrm{~S}_{4} \mathrm{X}_{3}(\mathrm{edpp})_{3}\right]^{+}(\mathrm{M}=\mathrm{Mo}$, W; $\mathrm{X}=\mathrm{Cl}, \mathrm{Br}) .[14,17]$ As previously mentioned, bromide terminal ligands in the $\left[\mathrm{W}_{3} \mathrm{~S}_{4} \mathrm{Br}_{3}(\mathrm{edpp})_{3}\right]^{+}$cluster are easily substituted by other halides and pseudohalides. Mechanistic investigation based on DFT methodologies revealed that the use of acetonitrile as solvent favors the ligand substitution reaction. Such a behavior towards terminal ligands exchange is a distinctive feature of the $\mathrm{W}_{3} \mathrm{~S}_{4}$ aminophosphino complexes in contrast with its diphosphino analogues, which are less reactive towards terminal ligand exchange.[14] In this context, we decided to investigate the reactivity of the halide aminophosphine complexes towards pure methanol but no reaction was detected. Hence, we choose to use a base such as trimethylamine $\left(\mathrm{Et}_{3} \mathrm{~N}\right)$ to promote the generation of methoxo groups and at the same time facilitate halide dissociation. Previous studies by our group, indicate that $\mathrm{Et}_{3} \mathrm{~N}$ abstracts one proton from the edpp amino group, a process which is accompanied by bromide dissociation.[22] Thus, the addition of an excess of $\mathrm{Et}_{3} \mathrm{~N}$ to a suspension of complexes $\mathbf{1}\left(\mathrm{BPh}_{4}\right)$ and $2\left(\mathrm{BPh}_{4}\right)$ in methanol resulted in the substitution of the three halide terminal ligands by methoxo groups in almost quantitative yields, according to scheme 1 . 

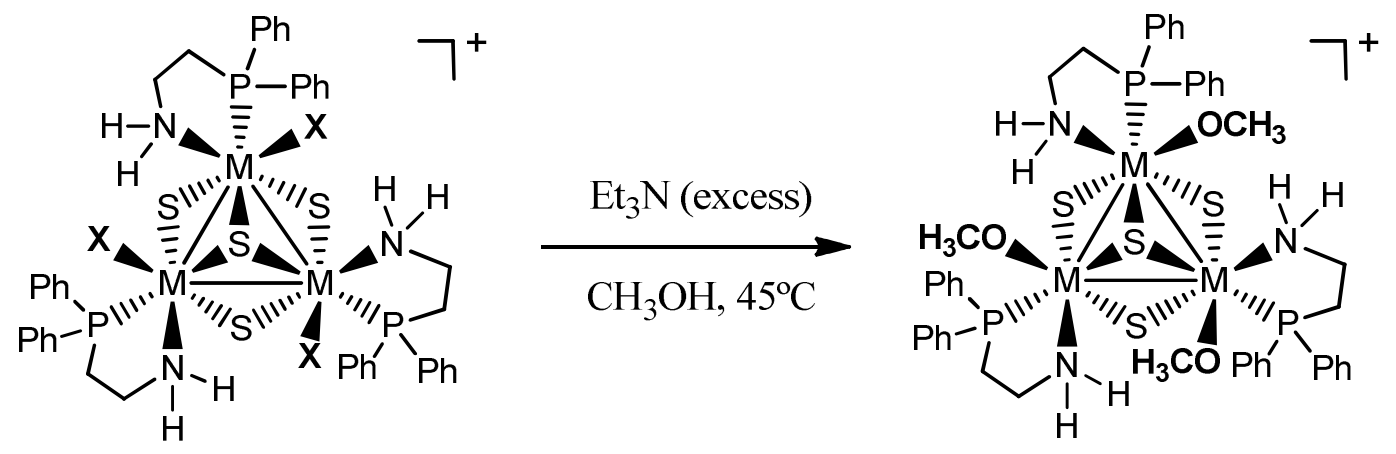

$\mathrm{M}=\mathrm{Mo}, \mathrm{W} ; \mathrm{X}=\mathrm{Cl}, \mathrm{Br}$

Scheme 1. Reaction scheme for the synthesis of $\left[\mathrm{M}_{3} \mathrm{~S}_{4}\left(\mathrm{OCH}_{3}\right)_{3}(\mathrm{edpp})\right]^{+}(\mathrm{M}=\mathrm{Mo}, \mathrm{W})$ cationic clusters.

The structures of cations $\mathbf{1}^{+}$and $\mathbf{2}^{+}$have been determined by single crystal X-ray diffraction as its tetraphenylborate salts. Figure 3 shows the ORTEP view of the $\mathbf{1}^{+}$and $\mathbf{2}^{+}$cations. Notice that $P$ and $M$ enantiomers [15, 23, 24] which result from the trinuclear cluster backbone chirality, have been highlighted. However, in our case both molybdenum and tungsten trimetallic complexes crystallize in the P-1 centrosymmetric space group, that is, they are obtained as racemic mixtures. The incomplete cubane-type structure present on the halide cluster precursors is retained and the three metal atoms define an approximately equilateral triangle with an average Mo-Mo bond distance of 2.7712 [10] $\AA$ and W-W bond distance of 2.7578[6] $\AA$. Each metal atom shows a pseudo-octahedral environment and its coordination sphere includes a phosphorous and a nitrogen atom from the edpp ligand, a methoxo group and one capping and two bridging sulfur atoms. The metal-metal and metal sulphur distances within the $\mathrm{M}_{3} \mathrm{~S}_{4}$ cluster core are similar than those observed for the halide precursors $\mathbf{1}^{+}$and $\mathbf{2}^{+}$. The metal-oxygen bond lengths of 2.018[6] $\AA$ for $\mathbf{1}^{+}$and 2.000[7] $\AA$ for $\mathbf{2}^{+}$, agree with the presence of a methoxo group. Similar distances have been observed for the metal-oxygen atoms in the $\left[\mathrm{Mo}_{3} \mathrm{~S}_{4}(\mathrm{dhprpe}-\mathrm{H})_{3}\right]^{+}(\mathrm{dhprpe}=$ 2-bis(bis(hydroxypropyl)-phosphino)ethane) $\quad[11], \quad\left[\mathrm{Mo}_{3} \mathrm{~S}_{4}(\mathrm{tdci})_{3}\right]^{4+} \quad(\operatorname{tdci}=\quad$ 1,3,5-trideoxy-1,3,5tris(dimethylamino)-cis-inositol)[25] and $\left[\mathrm{W}_{3} \mathrm{~S}_{4}(\mathrm{dhprpe}-\mathrm{H})_{3}\right]^{+}[26]$ complexes with average metaloxygen values of $2.018 \AA$ and 2.087 and $2.031 \AA$, respectively. The molecular arrangement of the halide precursors is transferred to the methoxo-terminated derivatives and only one isomer is formed with all three nitrogen atoms of the amino groups located above the plane defined by the three metal 
atoms. $[14,17]$ Therefore, edpp nitrogen atoms and oxygen atoms from the methoxo groups coordinated to the same metal center are found on the same side of the trimetallic plane with $\mathrm{O} \bullet \bullet \mathrm{N}$ distances in the range of $2.727(9)$ to $2.795(11) \AA$ for $\mathbf{1}^{+}$and $2.707(14)$ to $2.782(11) \AA$ for $\mathbf{2}^{+}$. The $\mathrm{O} \bullet \bullet \mathrm{N}$ distances between the oxygen atom coordinated to one metal atom and the nitrogen atom of the amino group coordinated to the adjacent metal atom are in the range of $3.178(10)$ to $3.670(9)$ for $\mathbf{1}^{+}$and $3.275(10)$ to 3.602(16) $\AA$ for $\mathbf{2}^{+}$. The solid state structure of complexes $\mathbf{1}^{+}$and $\mathbf{2}^{+}$is preserved in solution as evidenced by their ${ }^{31} \mathrm{P}\left\{{ }^{1} \mathrm{H}\right\}$ NMR spectra registered in $\mathrm{CD}_{3} \mathrm{CN}$, which shows a single signal at $40.3 \mathrm{ppm}$ for $\mathbf{1}^{+}$and at $18.5 \mathrm{ppm}$ for $\mathbf{2}^{+}$, attributed to the three equivalent phosphorous atoms from the aminophosphine ligands which are located above the metal plane.

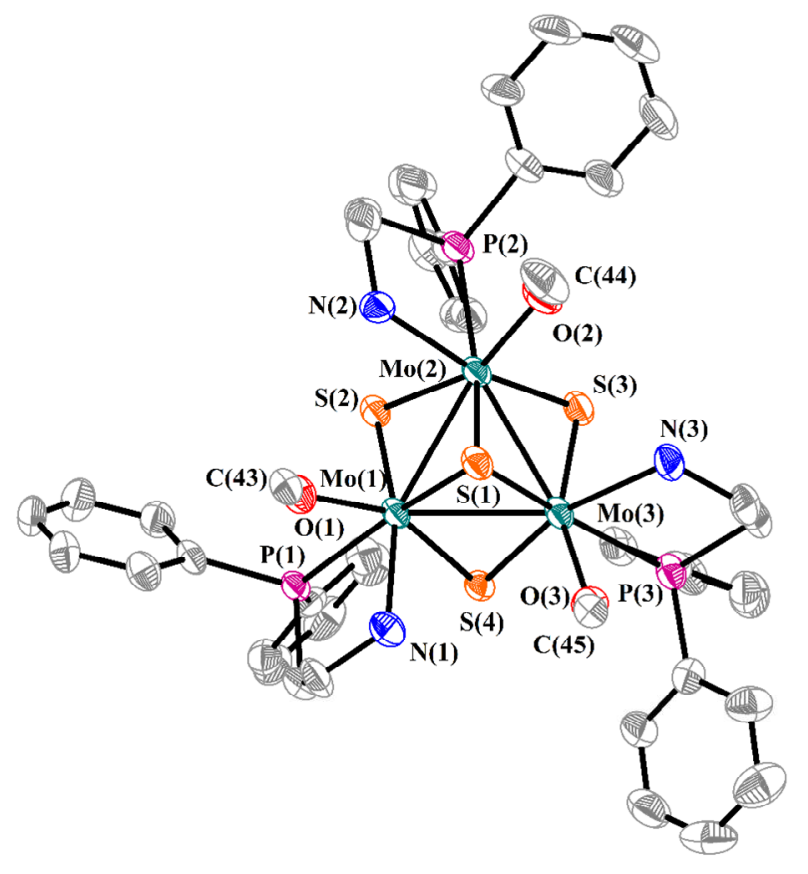

$\mathbf{1}^{+}$

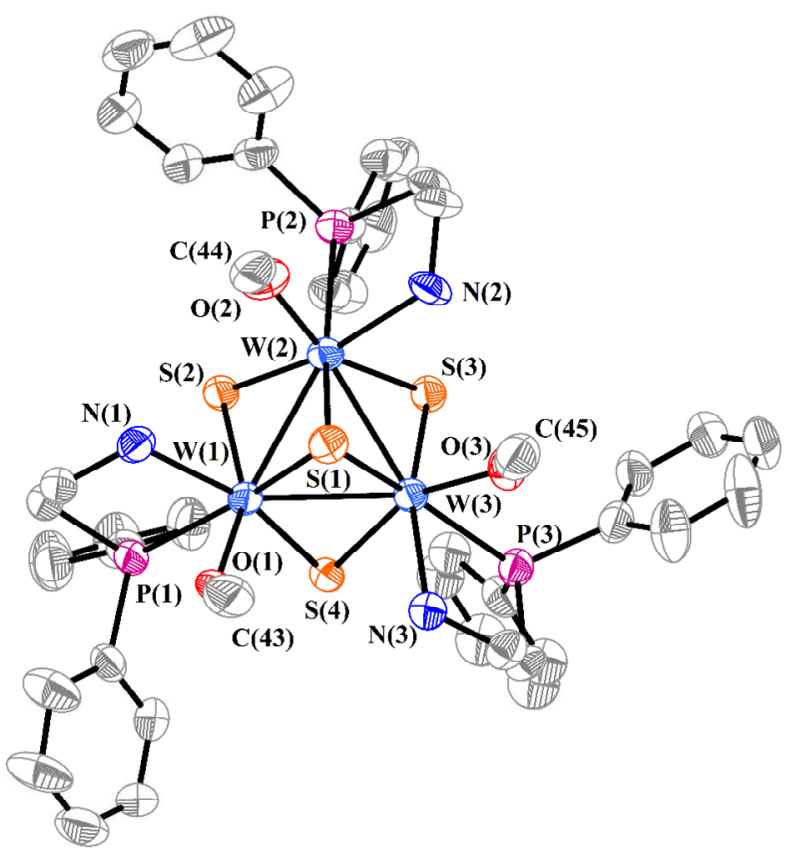

$2^{+}$

Figure 2. ORTEP representation of the $\mathbf{1}^{+}$(left) and $\mathbf{2}^{+}$(right) cations (ellipsoids drawn at the $50 \%$ probability level). Hydrogen atoms have been omitted for clarity. 
Table 1. Selected averaged bond distances $(\AA)$ for $\mathbf{1}\left(\mathrm{BPh}_{4}\right), \mathbf{2}\left(\mathrm{BPh}_{4}\right),\left[\mathrm{Mo}_{3} \mathrm{~S}_{4} \mathrm{Cl}_{3}(\mathrm{edpp})_{3}\right]\left(\mathrm{BPh}_{4}\right)$ and $\left[\mathrm{W}_{3} \mathrm{~S}_{4} \mathrm{Br}_{3}(\mathrm{edpp})_{3}\right]\left(\mathrm{BPh}_{4}\right)$.

\begin{tabular}{|c|c|c|c|c|}
\hline Length $(\AA)^{[\mathrm{a}]}$ & $\begin{array}{c}{\left[\mathrm{Mo}_{3} \mathrm{~S}_{4} \mathrm{Cl}_{3}(\mathrm{edpp})_{3}\right]\left(\mathrm{BPh}_{4}\right)} \\
{[17]}\end{array}$ & $\begin{array}{c}{\left[\mathrm{W}_{3} \mathrm{~S}_{4} \mathrm{Br}_{3}(\mathrm{edpp})_{3}\right]\left(\mathrm{BPh}_{4}\right)} \\
{[14]}\end{array}$ & $\mathbf{1}\left(\mathrm{BPh}_{4}\right)$ & $2\left(\mathrm{BPh}_{4}\right)$ \\
\hline M-M & $2.7464[7]$ & $2.7520[3]$ & $2.7712[10]$ & $2.7578[6]$ \\
\hline$M-\mu_{3}-S(1)$ & $2.3610[13]$ & $2.3450[16]$ & $2.375[2]$ & $2.381[3]$ \\
\hline$M-\mu-S(2)^{[b]}$ & $2.2961[12]$ & $2.3117[15]$ & $2.331[2]$ & $2.345[2]$ \\
\hline$M-\mu-S(2)^{[c]}$ & $2.2862[12]$ & $2.3091[15]$ & $2.302[2]$ & $2.308[2]$ \\
\hline M-P & $2.5413[14]$ & $2.5306[16]$ & $2.525[2]$ & $2.518[3]$ \\
\hline $\mathrm{M}-\mathrm{N}$ & $2.273[4]$ & $2.286[5]$ & $2.311[7]$ & $2.304[8]$ \\
\hline $\mathrm{M}-\mathrm{X}(\mathrm{X}=\mathrm{Cl}$ & $2.4626[15]$ & $2.6401[7]$ & $2.018[6]$ & $2.000[7]$ \\
\hline $\left.\mathrm{Br}, \mathrm{OCH}_{3}\right)$ & & & & \\
\hline
\end{tabular}

[a] Standard deviations for averaged values are given in square brackets. [b] M- $\mu-\mathrm{S}$ distance trans to Mo-X bond. [c] M- $\mu-S$ distance trans to M-N bond.

The tetraphenylborate salts of the $\mathbf{1}^{+}$and $\mathbf{2}^{+}$cations co-crystallize with methanol molecules. Interestingly, in the structure of the methoxo-terminated molybdenum $\mathbf{1}^{+}$cluster the methanol molecule is located with the oxygen atoms pointing towards the amino group bonded to one metal centre and the oxygen atom of the methoxo ligand coordinated to the adjacent metal atom (see figure 3 ). Inspection of the interatomic distances reveals the presence of a $(\mathrm{NH})-\mathrm{H} \bullet \bullet-\mathrm{OH}-\left(\mathrm{CH}_{3}\right)$ hydrogen bond with $\mathrm{N}-\mathrm{O}$ distaces of 2.918(11) A. In addition, the $\mathrm{OH}$ group from the methanol molecule also interacts with the oxygen atom of the vicinal methoxo group at a bond length of $2.799(10) \AA$. Such an observation is a crystallographic evidence of the non-innocent role of the amino groups which can be potentially deprotonated, facilitating the substitution of the halide ligand in the presence of methanol, in agreement with our previous studies on the reactivity of $\left[\mathrm{W}_{3} \mathrm{~S}_{4} \mathrm{Br}_{3}(\mathrm{edpp})_{3}\right]^{+}$complexes towards bases. [22] 


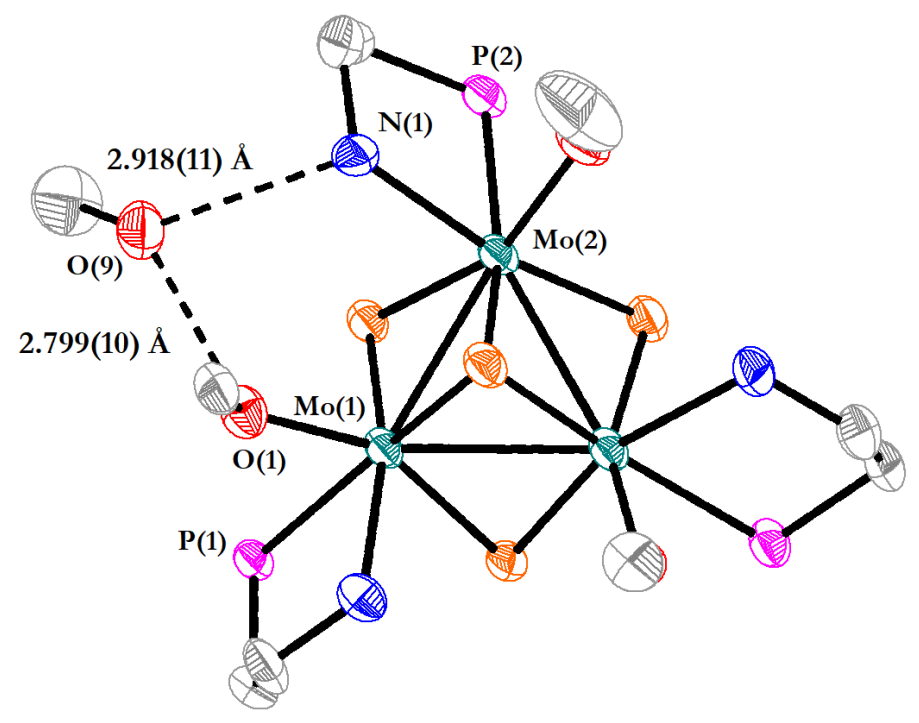

Figure 3. ORTEP representation of the interaction between $\mathbf{1}^{+}$cation and one of the co-crystallized methanol molecule (ellipsoids $50 \%$ probability). Phenyl rings and hydrogen atoms have been omitted for clarity.

\section{Gas phase dissociation of $1^{+}$and $2^{+}$complexes}

The ESI mass spectra of both aminophosphine complexes, obtained under gentle conditions $(\mathrm{Uc}=5 \mathrm{~V})$ show a peak centered at 1198 for $\mathbf{1}^{+}$, and at $1460 \mathrm{~m} / \mathrm{z}$ for $\mathbf{2}^{+}$attributed to the pseudomolecular cation on the basis of the $\mathrm{m} / \mathrm{z}$ value and its characteristic isotopic pattern. The most prominent peak in the isotopomer pattern of $\mathbf{1}^{+}$and $\mathbf{2}^{+}$was mass selected and used to study their characteristic gas-phase dissociation. The collision induced dissociation (CID) spectra for $\mathbf{1}^{+}$cations is shown in Figure 4 . The main fragmentation channel of $\mathbf{1}^{+}$at collision energies (CE) Elaboratory $=20 \mathrm{eV}$ consists of a sequential loss of methanol molecules $(32 \mathrm{Da})$ molecules to give unsaturated $\left[\mathrm{Mo}_{3} \mathrm{~S}_{4}\left(\mathrm{OCH}_{3}\right)_{2}(\mathrm{edpp})_{2}(\mathrm{edpp}-\mathrm{H})\right]^{+}$ (m/z 1166), $\left[\mathrm{Mo}_{3} \mathrm{~S}_{4}\left(\mathrm{OCH}_{3}\right)(\mathrm{edpp})(\mathrm{edpp}-\mathrm{H})_{2}\right]^{+}(\mathrm{m} / \mathrm{z} 1134)$ and $\left[\mathrm{Mo}_{3} \mathrm{~S}_{4}(\mathrm{edpp}-\mathrm{H})_{3}\right]^{+}(\mathrm{m} / \mathrm{z} 1102)$ cations. At $\mathrm{CE} \mathrm{E}_{\text {laboratory }}=30 \mathrm{eV}$, the triply unsaturated species dominates the spectrum. A similar gas-phase behavior is observed for the $\mathbf{2}^{+}$complex which sequentially loses methanol molecules to yield the $\left[\mathrm{W}_{3} \mathrm{~S}_{4}(\text { edpp-H})_{3}\right]^{+}(\mathrm{m} / \mathrm{z}$ 1364) unsaturated cation. Such an unsaturated species was previously described in our study on the gas phase behavior of the hydroxo $\left[\mathrm{W}_{3} \mathrm{~S}_{4}(\mathrm{OH})_{3}(\mathrm{edpp})_{3}\right]^{+}$cluster. [22] This behaviour resembles that of the halide $\left[\mathrm{Mo}_{3} \mathrm{~S}_{4} \mathrm{X}_{3}(\mathrm{edpp})_{3}\right]^{+}$cluster precursors. A proton transfer mechanism from 
the amino group to the halide atom bound to the same metal accounts for the sequential losses of three HX molecules with the concomitant formation of unsaturated metal/imine $\mathrm{M}=\mathrm{NH}$ cluster species.[17]

1198
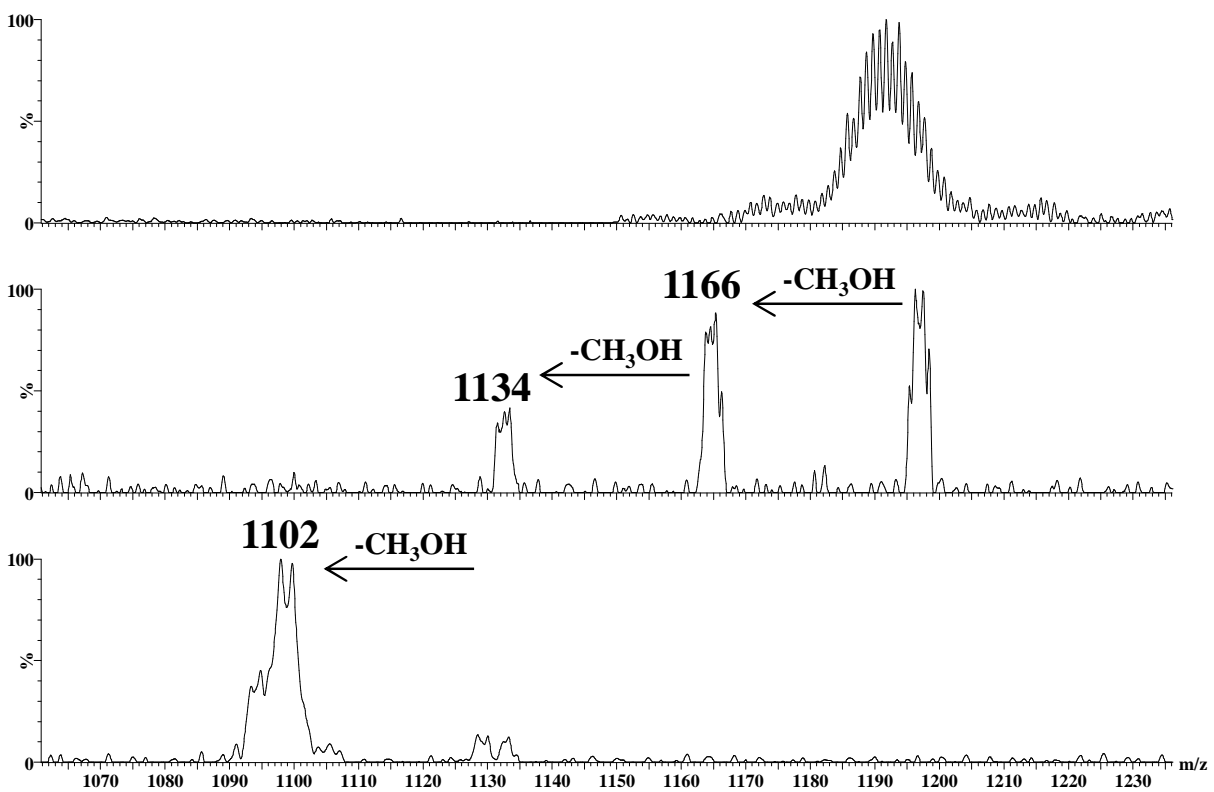

Figure 4. ESI mass spectrum at $\mathrm{U}_{\mathrm{c}}=5 \mathrm{~V}$ (top) and product ion spectra at two collision energies $E_{\text {laboratory }}$ $=20 \mathrm{eV}$ (middle) and $\mathrm{E}_{\text {laboratory }}=30 \mathrm{eV}$ (bottom) of mass selected $\left[\mathrm{Mo}_{3} \mathrm{~S}_{4}\left(\mathrm{OCH}_{3}\right)_{3}(\mathrm{edpp})_{3}\right]^{+}\left(\mathbf{1}^{+}\right)$.

\section{Experimental Section}

\section{Materials and methods}

All reactions were carried out under a nitrogen atmosphere using standard Schlenck techniques. Compounds $\left[\mathrm{Mo}_{3} \mathrm{~S}_{4} \mathrm{Cl}_{3}(\mathrm{edpp})_{3}\right] \mathrm{Cl}$ [17] and $\left[\mathrm{W}_{3} \mathrm{~S}_{4} \mathrm{Br}{ }_{3}(\text { edpp })_{3}\right] \mathrm{Br}$ [14] were prepared by following literature procedures. Addition of $\mathrm{NaBPh}_{4}$ to concentrated methanol solutions of $\left[\mathrm{Mo}_{3} \mathrm{~S}_{4} \mathrm{Cl} l_{3}(\mathrm{edpp})_{3}\right] \mathrm{Cl}$ or $\left[\mathrm{W}_{3} \mathrm{~S}_{4} \mathrm{Br}_{3}(\mathrm{edpp})_{3}\right] \mathrm{Br}$ causes precipitation of the corresponding tetraphenylborates salts. Solvents were dried and degassed by standard methods before use. The remaining reactants were obtained from commercial sources and used as received. ${ }^{31} \mathrm{P}\left\{{ }^{1} \mathrm{H}\right\}$ NMR spectra were recorded on a Varian Innova 300 MHz using $\mathrm{CD}_{3} \mathrm{CN}$ as solvents and referenced to $85 \% \mathrm{H}_{3} \mathrm{PO}_{4}$. 


\section{Synthesis of $\left[\mathrm{Mo}_{3} \mathrm{~S}_{4}\left(\mathrm{OCH}_{3}\right)_{3}(\mathrm{edpp})_{3}\right] \mathrm{BPh}_{4}\left(\mathrm{1}_{\left.\left(\mathrm{BPh}_{4}\right)\right)}\right.$}

A green suspension of $\left[\mathrm{Mo}_{3} \mathrm{~S}_{4} \mathrm{Cl}_{3}(\mathrm{edpp})_{3}\right] \mathrm{BPh}_{4}(0.050 \mathrm{~g}, 0.033 \mathrm{mmol})$ in methanol $(20 \mathrm{~mL})$ was treated with triethylamine $(0.167 \mathrm{~mL}, 1.198 \mathrm{mmol})$ under nitrogen and the reaction mixture was heated at 45 $50^{\circ} \mathrm{C}$ overnight. Solution turns to dark green colour. After removing one-half of the solvent under reduced pressure, the desired product was precipitated with diethyl ether. Finally, the dark green solid was separated by filtration, washed with water, diethyl ether and dried under high vacuum to yield 0.043 $\mathrm{g}(86 \%$ yield $)$ of an air stable product characterized as $\mathbf{1}\left(\mathrm{BPh}_{4}\right)$.

${ }^{31} \mathrm{P}\left\{{ }^{1} \mathrm{H}\right\}$ NMR $\left(\mathrm{CD}_{3} \mathrm{CN}, 121 \mathrm{MHz}\right) \delta=40.3$ (s, 3P). ESI-MS $\left(\mathrm{CH}_{3} \mathrm{CN}, 5 \mathrm{~V}\right) \mathrm{m} / \mathrm{z}: 1198\left[\mathrm{M}^{+}\right] . \mathrm{IR}(\mathrm{KBr}): \bar{v}$ $=1434(\mathrm{~s}), 1098(\mathrm{~s}) 955(\mathrm{~m}), 824(\mathrm{w}), 689(\mathrm{~s}), 521(\mathrm{~s}), 445(\mathrm{w}) . \mathrm{UV} / \mathrm{Vis}\left(\mathrm{CH}_{3} \mathrm{CN}\right): \lambda_{\max }(\varepsilon) 345$ (7135.9), 398 (4815.4), $656 \mathrm{~nm}$ (367.5 $\mathrm{M}^{-1} \mathrm{~cm}^{-1}$ ). Anal. calcd for $\mathrm{Mo}_{3} \mathrm{~S}_{4} \mathrm{C}_{69} \mathrm{H}_{77} \mathrm{~N}_{3} \mathrm{P}_{3} \mathrm{O}_{3} \mathrm{~B}$ (1516.18): C, 54.7; H, 5.1; N, 2.8. Found: C, 54.6; H, 5.3; N, 2.7.

\section{Synthesis of $\left[\mathrm{W}_{3} \mathrm{~S}_{4}\left(\mathrm{OCH}_{3}\right)_{3}(\mathrm{edpp})_{3}\right] \mathrm{BPh}_{4}\left(2\left(\mathrm{BPh}_{4}\right)\right)$}

A blue suspension of $\left[\mathrm{W}_{3} \mathrm{~S}_{4} \mathrm{Br}_{3}(\mathrm{edpp})_{3}\right] \mathrm{BPh}_{4}(0.050 \mathrm{~g}, 0.026 \mathrm{mmol})$ in methanol $(20 \mathrm{~mL})$ was treated with triethylamine $(0.135 \mathrm{~mL}, 0.969 \mathrm{mmol})$ under nitrogen and the reaction mixture was heated at 45 $50^{\circ} \mathrm{C}$ overnight. Solution turns to reddish-purple colour. After removing one-half of the solvent under reduced pressure, the desired product was precipitated by adding diethyl ether. Finally, the reddishpurple solid was separated by filtration, washed with water, diethyl ether and dried under high vacuum to yield $0.045 \mathrm{~g}$ (96\% yield) of an air stable product characterized as $2\left(\mathrm{BPh}_{4}\right)$.

${ }^{31} \mathrm{P}\left\{{ }^{1} \mathrm{H}\right\} \mathrm{NMR}\left(\mathrm{CD}_{3} \mathrm{CN}, 121 \mathrm{MHz}\right) \delta=18.5\left(3 \mathrm{P}, \mathrm{s},{ }^{1} \mathrm{~J}_{\mathrm{P}-\mathrm{W}}=93.7 \mathrm{~Hz}\right)$. ESI-MS $\left(\mathrm{CH}_{3} \mathrm{CN}, 5 \mathrm{~V}\right) \mathrm{m} / \mathrm{z}: 1460$ [M+]. IR (KBr): $\bar{v}=1435(\mathrm{~s}), 1100(\mathrm{~s}) 1301(\mathrm{~s}), 952(\mathrm{~m}), 817(\mathrm{w}), 692(\mathrm{~s}), 523(\mathrm{~s}), 447(\mathrm{w})$. UV/Vis $\left(\mathrm{CH}_{3} \mathrm{CN}\right): \lambda_{\max }$ (E) 330 (8054.5), 375 (6564.2), $641 \mathrm{~nm}$ (437.4 $\left.\mathrm{M}^{-1} \mathrm{~cm}^{-1}\right)$. Anal. calcd for $\mathrm{W}_{3} \mathrm{~S}_{4} \mathrm{C}_{69} \mathrm{H}_{77} \mathrm{~N}_{3} \mathrm{P}_{3} \mathrm{O}_{3} \mathrm{~B}$ (1779.88): C, 46.6; H, 4.4; N, 2.4. Found: $\mathrm{C}, 46.9 ; \mathrm{H}, 4.3 ; \mathrm{N}, 2.6$. 


\section{$\mathrm{X}$-ray data collection and structure refinement}

Suitable crystals for X-ray studies of the tetraphenylborate salts of $\mathbf{1}^{+}$and $\mathbf{2}^{+}$were grown by slow evaporation of a sample solution in methanol. X-ray diffraction experiments were carried out on a Agilent Supernova diffractometer equipped with an Atlas CCD detector using Mo-K $\alpha$ radiation $(\lambda=$ $0.71073 \AA)$ for $\mathbf{1}_{2}\left(\mathrm{BPh}_{4}\right)_{2} \cdot 4\left(\mathrm{CH}_{3} \mathrm{OH}\right)$ and $\mathrm{Cu}-\mathrm{K} \alpha$ radiation $(\lambda=1.54184 \AA)$ for $\mathbf{2}_{2}\left(\mathrm{BPh}_{4}\right)_{2} \cdot\left(\mathrm{CH}_{3} \mathrm{OH}\right)$. Absorption corrections based on the multi-scan method were applied.[27, 28] The structures were solved by direct methods in SHELXS-2013 and refined by the least squares method with the program SHELXL-2013 using the OLEX software package. [29, 30] Two crystallographically independent $\mathbf{1}^{+}$or $\mathbf{2}^{+}$units are present in each structure. The remaining peaks after the location of the clusters and the anions were assigned to carbon and oxygen atoms from methanol solvent molecules and refined anisotropically. The hydrogen atoms bonded to carbon, nitrogen and oxygen were included at their idealized position and refined isotropically as riders except that bonded to $\mathrm{O}(10)$ in $\mathbf{1}_{2}\left(\mathrm{BPh}_{4}\right)_{2} \cdot 4\left(\mathrm{CH}_{3} \mathrm{OH}\right)$ due to its high thermal parameter $\left(\mathrm{Ueq}=0.200 \AA^{2}\right)$. The structural figures were drawn using DIAMOND visual crystal structure information system software.[31]

Crystal data for $\mathbf{1}_{2}\left(\mathrm{BPh}_{4}\right)_{2} \cdot 4\left(\mathrm{CH}_{3} \mathrm{OH}\right): \mathrm{C}_{142} \mathrm{H}_{169} \mathrm{~B}_{2} \mathrm{Mo}_{6} \mathrm{~N}_{6} \mathrm{O}_{10} \mathrm{P}_{6} \mathrm{~S}_{8}, M=3159.38$, triclinic, space group $P-1, \mathrm{a}=18.3620(4) \AA, \mathrm{b}=20.3453(3) \AA, c=21.8810(4) \AA, \alpha=113.0821(16)^{\circ}, \beta=101.2477(17)^{\circ}, \gamma=$ 97.2159(15) ${ }^{\circ}, \quad V=7188.1(2) \AA^{3}, T=149.9(3) \mathrm{K}, Z=2, \mu($ Mo $\mathrm{K} \alpha) \quad 0.749 \mathrm{~mm}^{-1}$. Reflections collected/unique $=89411 / 25357\left(R_{\text {int }}=0.0585\right)$. Final refinement converged with $R_{1}=0.1019$ and $w R_{2}$ $=0.2101$ for all reflections, $\mathrm{GOF}=1.067, \mathrm{max} / \mathrm{min}$ residual electron density $1.75 /-1.20 \mathrm{e} \cdot \AA^{-3}$.

Crystal data for $2_{2}\left(\mathrm{BPh}_{4}\right)_{2} \cdot\left(\mathrm{CH}_{3} \mathrm{OH}\right): \mathrm{C}_{139} \mathrm{H}_{158} \mathrm{~B}_{2} \mathrm{~N}_{6} \mathrm{O}_{7} \mathrm{P}_{6} \mathrm{~S}_{8} \mathrm{~W}_{6}, M=3591.72$, triclinic, space group $P-1$, a $=14.7148(4) \AA, \mathrm{b}=19.2420(4) \AA, c=25.4644(4) \AA, \alpha=90.8329(15)^{\circ}, \beta=92.4448(16)^{\circ}, \gamma=$ 108.203(2) ${ }^{\circ}, V=6840.0(3) \AA^{3}, T=150.00(10) \quad \mathrm{K}, Z=2, \mu(\mathrm{Cu} \mathrm{K \alpha}) 11.307 \mathrm{~mm}^{-1}$. Reflections collected/unique $=128421 / 24156\left(R_{\text {int }}=0.0618\right)$. Final refinement converged with $R_{1}=0.0707$ and $\mathrm{w} R_{2}=0.1409$ for all reflections, $\mathrm{GOF}=1.068, \mathrm{max} / \mathrm{min}$ residual electron density $3.40 /-1.69 \mathrm{e} \cdot \AA^{-3}$. 


\section{Mass Spectrometry Experiments}

ESI and tandem mass experiments have been conducted on a Quattro LC (quadrupole-hexapolequadrupole) mass spectrometer with an orthogonal Z-spray electrospray interface (Waters, Manchester, UK). Sample solutions have been infused via syringe pump directly connected to the ESI source at a flow rate of $10 \mu \mathrm{L} / \mathrm{min}$ and a capillary voltage of $3.5 \mathrm{kV}$ was used in the positive scan mode. Nitrogen has been used as the desolvation gas and nebulization gas, at a flow of $7.5 \mathrm{~L} / \mathrm{min}$ and $1.3 \mathrm{~L} / \mathrm{min}$, respectively. ESI mass spectra of acetonitrile solutions of $\mathbf{1}\left(\mathrm{BPh}_{4}\right)$ and $\mathbf{2}\left(\mathrm{BPh}_{4}\right)$ recorded at low voltages (typically $\mathrm{U}_{\mathrm{c}}=5 \mathrm{~V}$ ) promote the gas phase formation of pseudomolecular $\mathbf{1}^{+}$and $\mathbf{2}^{+}$cations. To do research on their characteristic gas-phase dissociation, we studied the collision induced dissociation (CID) spectra of $\mathbf{1}^{+}$and $\mathbf{2}^{+}$cationic clusters. For CID spectra, cations $\mathbf{1}^{+}$and $\mathbf{2}^{+}$(generated at low cone voltages) were mass-selected by using a first quadrupole (Q1) and interacted with argon in the hexapole collision cell under multiple-collision conditions (typically $7 \times 10^{-4} \mathrm{mbar}$ ) at variable collision energies (typically $E_{\text {lab }}=5-30 \mathrm{eV}$ ) while scanning the second quadrupole (Q2) to monitor the ionic products of fragmentation. An isolation width of $1 \mathrm{Da}$ was used in the first quadrupole analyzer. Isotope experimental patterns were compared with theoretical patterns obtained using the MassLynx 4.0 program.[32]

\section{Conclusions}

In conclusion, methoxo-terminated trimetallic molybdenum and tungsten clusters containing aminophosphine ligands have been synthesized for the first time by ligand substitution from halide $\left[\mathrm{M}_{3} \mathrm{~S}_{4} \mathrm{X}_{3}(\text { edpp })_{3}\right]^{+}(\mathrm{M}=\mathrm{Mo}, \mathrm{W} ; \mathrm{X}=\mathrm{Cl}, \mathrm{Br})$ precursors. They have been fully characterized by spectroscopic and single crystal x-ray diffraction techniques. Their molecular structure confirm the presence of terminal methoxo groups directly coordinated to molybdenum and tungsten centres. Gasphase fragmentation of these novel alcoxo-terminated clusters ions show the sequential losses of three methanol molecules to yield metal/imine $\mathrm{M}=\mathrm{NH}$ cluster species. 
Supporting Information (see footnote on the first page of this article): CCDC reference numbers $1896337\left(\mathbf{1}_{2}\left(\mathrm{BPh}_{4}\right)_{2} \cdot 4\left(\mathrm{CH}_{3} \mathrm{OH}\right)\right)$ and $1896338\left(\mathbf{2}_{2}\left(\mathrm{BPh}_{4}\right)_{2} \cdot\left(\mathrm{CH}_{3} \mathrm{OH}\right)\right)$.

\section{Acknowledgments}

Financial support from the Spanish Ministerio de Economía y Competitividad and FEDER funds of the EU (Grants CTQ2011-23157 and CTQ2015-65207-P), Universitat Jaume I (UJI-B2017-44) and Generalitat Valenciana (PrometeoII/2014/022) is gratefully acknowledged. The authors also thank the Serveis Centrals d'Instrumentació Cientifica (SCIC) of the Universitat Jaume I for providing us with the mass spectrometry, NMR and X-ray facilities. T. Beltrán thanks the Spanish Ministerio de Ciencia e Innovación (MICINN) for a doctoral fellowship (FPI).

\section{References}

[1] D.J. Darensbourg, K.M. Sanchez, J.H. Reibenspies, A.L. Rheingold, J. Am. Chem. Soc., 111 (1989) 7094-7103.

[2] T. Fan, X. Chen, Z. Lin, Chem. Commun., 48 (2012) 10808-10828.

[3] J. Zhao, H. Hesslink, J.F. Hartwig, J. Am. Chem. Soc., 123 (2001) 7220-7227.

[4] E. Hevia, J. Perez, L. Riera, V. Riera, I. del Rio, S. Garcia-Granda, D. Miguel, Chem. Eur. J., 8 (2002) 4510-4521.

[5] F. Estevan, M. Feliz, R. Llusar, J.A. Mata, S. Uriel, Polyhedron, 20 (2001) 527-535.

[6] M.G. Basallote, F. Estevan, M. Feliz, M.J. Fernandez-Trujillo, D.A. Hoyos, R. Llusar, S. Uriel, C. Vicent, Dalton Trans., (2004) 530-536.

[7] A.S.G. Algarra, M.G. Basallote, M. Jesus Fernandez-Trujillo, R. Llusar, V.S. Safont, C. Vicent, Inorg. Chem., 45 (2006) 5774-5784.

[8] R. Llusar, C. Vicent, Trinuclear Molybdenum and Tungsten Cluster Chalcogenides: From Solid State to Molecular Materials, in: Inorganic Chemistry in Focus III, G. Meyer, D. Naumann, L. Wesermann, Eds., WILEY-VCH: Weinheim, Germany, 2006; Chapter 7.

[9] A.G. Algarra, M.G. Basallote, M.J. Fernandez-Trujillo, E. Guillamon, R. Llusar, M.D. Segarra, C. Vicent, Inorg. Chem., 46 (2007) 7668-7677.

[10] T.F. Beltran, M. Feliz, R. Llusar, J.A. Mata, V.S. Safont, Organometallics, 30 (2011) 290-297. 
[11] M.G. Basallote, M. Jesus Fernandez-Trujillo, J. Angel Pino-Charnorro, T.F. Beltran, C. Corao, R. Llusar, M. Sokolov, C. Vicent, Inorg. Chem., 51 (2012) 6794-6802.

[12] T.F. Beltran, R. Llusar, M. Sokolov, M.G. Basallote, M. Jesus Fernandez-Trujillo, J. Angel PinoChamorro, Inorg. Chem., 52 (2013) 8713-8722.

[13] A.L. Gushchin, Y.A. Laricheva, P.A. Abramov, A.V. Virovets, C. Vicent, M.N. Sokolov, R. Llusar, Eur. J. Inorg. Chem., (2014) 4093-4100.

[14] T.F. Beltran, J. Angel Pino-Chamorro, M. Jesus Fernandez-Trujillo, V.S. Safont, M.G. Basallote, R. Llusar, Inorg. Chem., 54 (2015) 607-618.

[15] E.M. Guillamon, M. Blasco, R. Llusar, Inorg. Chim. Acta, 424 (2015) 248-253.

[16] E. Pedrajas, I. Sorribes, K. Junge, M. Beller, R. Llusar, Chemcatchem, 7 (2015) 2675-2681.

[17] T.F. Beltran, V.S. Safont, R. Llusar, Eur. J. Inorg. Chem., (2016) 5171-5179.

[18] M.G. Basallote, M. Feliz, M.J. Fernandez-Trujillo, R. Llusar, V.S. Safont, S. Uriel, Chem. Eur. J., 10 (2004) 1463-1471.

[19] T.F. Beltran, M. Feliz, R. Llusar, V.S. Safont, C. Vicent, Eur. J. Inorg. Chem., 2013 (2013) $5797-$ 5805 .

[20] C. Vicent, M. Feliz, R. Llusar, J. Phys. Chem. A, 112 (2008) 12550-12558.

[21] T.F. Beltran, M. Feliz, R. Llusar, V.S. Safont, C. Vicent, Catal. Today, 177 (2011) 72-78.

[22] J.A. Pino-Chamorro, T.F. Beltran, M.J. Fernandez-Trujillo, M.G. Basallote, R. Llusar, A.G. Algarra, Eur. J. Inorg. Chem., (2017) 5006-5014.

[23] M. Feliz, E. Guillamon, R. Llusar, C. Vicent, S.E. Stiriba, J. Perez-Prieto, M. Barberis, Chem. Eur. J., 12 (2006) 1486-1492.

[24] A.G. Algarra, M.G. Basallote, M.J. Fernandez-Trujillo, M. Feliz, E. Guillamon, R. Llusar, I. Sorribes, C. Vicent, Inorg. Chem., 49 (2010) 5935-5942.

[25] K. Hegetschweiler, M. Worle, M.D. Meienberger, R. Nesper, H.W. Schmalle, R.D. Hancock, Inorg. Chim. Acta, 250 (1996) 35-47.

[26] T. F. Beltrán, PhD Thesis, Universitat Jaume I, 2013.

[27] CrysAlisPro, Version 171.36.24, Agilent Technologies, Santa Clara, CA, 2012.

[28] R.C. Clark, J.S. Reid, Acta Crystallographica Section A, 51 (1995) 887-897.

[29] G.M. Sheldrick, Acta Crystallographica Section A, 64 (2008) 112-122.

[30] O.V. Dolomanov, L.J. Bourhis, R.J. Gildea, J.A.K. Howard, H. Puschmann, J. Appl. Crystallogr., 42 (2009) 339-341.

[31] K. Brandenburg, H. Putz, Diamond: Crystal and Molecular Structure Visualization,Crystal Impact, Bonn, 2008, http://www.crystalimpact.com/diamond.

[32] MassLynx, Version 4.1 SCN 639, Waters Inc., Milford, MA, 2008. 


\section{Graphical abstract}
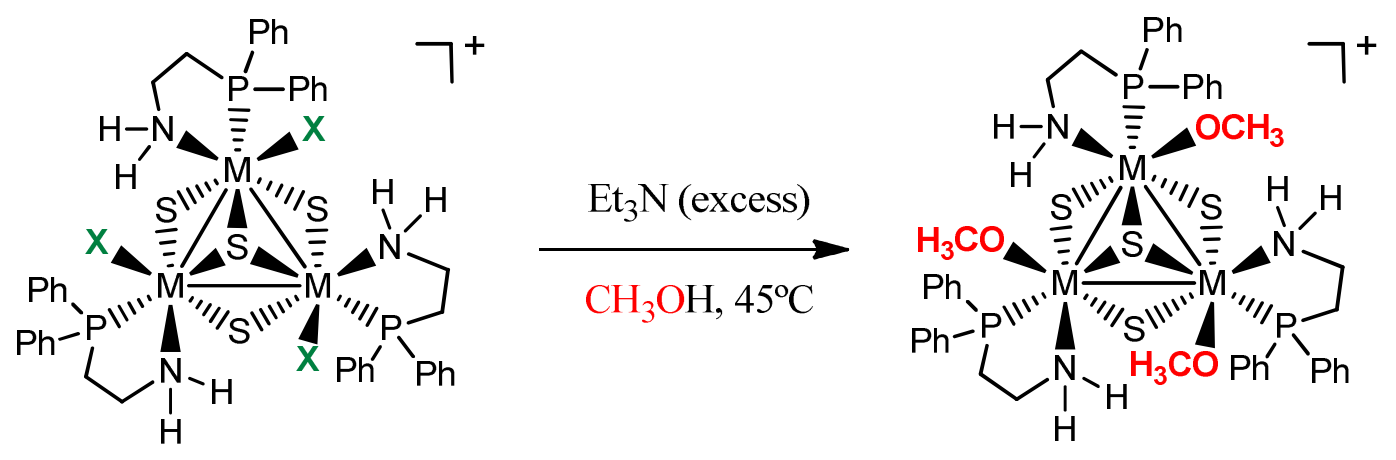

$\mathrm{M}=\mathrm{Mo}, \mathrm{W} ; \mathrm{X}=\mathrm{Cl}, \mathrm{Br}$

New methoxo-terminated M3S4 (M=Mo,W) clusters bearing aminophosphine ligands have been fully characterized by spectroscopic, mass spectrometric and X-ray techniques. Gas-phase dissociation of the novel methoxo cluster cations using ESI tandem mass spectrometry is also presented. 